\title{
Analysis of Propylene Glycol Raw Supplier Selection using the Analytic Hierarchy Process Method
}

\author{
Yusuf Budiono and Dudi Permana
}

\section{ABSTRACT}

The purpose of this research is to study the priority order of the criteria and sub-criteria that influence supplier selection and to find out which supplier or supplier of the best raw material, which best meets the criteria for selecting the supplier that should be selected. In this study only limited to 4 criteria, namely price, quality, warranty, and delivery. This research is a qualitative research using the calculation method used is the Analytic Hierarchy Process (AHP) method. The software used in using the Analytic Hierarchy Process (AHP) method is version 3.2 super decisions. The findings show that the price criterion is the most important priority for companies to pay attention to, followed by delivery, quality, and warranty criteria.

Keywords: AHP, procurement, supplier selection.
Submitted : February 26, 2021

Published : March 23, 2021

ISSN: 2507-1076

DOI: $10.24018 /$ ejbmr.2021.6.2.783

\section{Yusuf Budiono}

Magister of Management, Mercu Buana University, Jakarta, Indonesia.

(e-mail: yusufbudiono.tgssp@ ${ }^{\circledR}$ gmail.com) Dudi Permana*

Lecturer of Postgraduate, Mercu Buana

University, Jakarta, Indonesia.

(e-mail: dudi.permana ${ }^{@}$ mercubuana.ac.id)

T. C. Author

*Corresponding Author

\section{INTRODUCTION}

Supplier selection is one of the important things in purchasing activities for a company. These activities are part of supply chain management which will later be considered in determining the selling price of the product. When the wrong supplier is chosen, the company must be prepared to accept the consequences of the product that has been purchased. One example is the price that is too expensive compared to the supplier's competitors or in terms of lower quality and of course the speed of delivery made by the supplier. Supplier delays certainly create obstacles in the production process. One company that is engaged in manufacturing food raw materials in Tangerang City has produced various premix flours, pastas, and various food raw materials where they have been delayed by suppliers and resulted in the emergence of many revisions to production plans. The raw material used is propylene glycol, where 4 suppliers are used but have not been able to choose a priority supplier. The number of production planning revisions itself increased from 19\% in 2017 to $23 \%$ in 2018.

\begin{tabular}{ccccc}
\multicolumn{5}{c}{ TABLE I: PARETO RAW MATERIAL 2016-2018 } \\
\hline \multirow{2}{*}{ No } & Product Name & 2016 & 2017 & 2018 \\
\cline { 3 - 5 } 1 & Rafination Sugar & 4450 & 2250 & 2355 \\
2 & Lame Quick CE2956 & 126 & 58 & 131 \\
3 & Propylene Glycol & 230 & 161 & 292 \\
4 & Lame Quick CE6630 & 22 & 40 & 63 \\
5 & Palm Oil & 672 & 418 & 869 \\
\hline \multicolumn{2}{l}{ Source: Q1 2019 business review report. }
\end{tabular}

Based on the data above, of course it can be seen that the five raw materials are pareto raw materials in producing customized powders and customize hours where the researcher limits the research problem to propylene glycol raw materials because there are 5 suppliers that are difficult to choose to fit the criteria desired by the company. Propylene glycol is a product derived from Petroleum.

Propylene glycol is an additive which is also commonly used in various food products such as salads, ice cream, food coloring agents, popcorn, sour cream, and cake mixes. In the food industry it can also be used as a flavoring, a solvent for food coloring, food packaging softeners, food anti-adhesive agents, and the like. This type of liquid has no odor and no color. Propylene glycol can also be used for dry mix so that the cake has a soft texture.

TABLE II: PRODUCTION SCHEDULE REVISION FREQUENCY 2016-2018

\begin{tabular}{cccc}
\hline Revised Production & \multicolumn{3}{c}{ Frequency in times } \\
\cline { 2 - 4 } Plan & 2016 & 2017 & 2018 \\
\hline January & 10 & 11 & 14 \\
February & 8 & 9 & 15 \\
March & 7 & 9 & 9 \\
April & 11 & 8 & 13 \\
May & 12 & 11 & 12 \\
June & 10 & 12 & 15 \\
July & 9 & 13 & 16 \\
August & 8 & 10 & 12 \\
September & 6 & 10 & 10 \\
October & 7 & 9 & 9 \\
November & 9 & 12 & 9 \\
December & 7 & 10 & 18 \\
Total & 104 & 124 & 152 \\
Increasing & & $19 \%$ & $23 \%$ \\
\hline
\end{tabular}

Source: Q1 2019 business review report.

Based on these data, it can be seen that the production planning revision increases every year. In fact, in the production process, planning revisions are highly avoided because they make the production process not optimal. There are many things that have a direct impact when the production planning revision occurs, including the warehouse part which must re-prepare the raw materials 
used during the production process. If the time needed is not sufficient to re-prepare the raw materials that were replaced during the revision of the production planning, over time will of course occur. According to the supply chain approach, one way to increase productivity is to strengthen the production unit, namely between manufacturers and suppliers. One of the ways to integrate manufacture and supplier is the good relationship that exists between supplier and customer as well as making the right decision in supplier selection. Making the right decisions in choosing suppliers can be a solution that can be taken in dealing with these problems, but the selection must be tailored to the needs of the company.

\section{LITERATURE REVIEW}

One method that can be used to solve problems in supplier selection is the AHP (Analytical Hierarchy Process) method. This method includes qualitative and quantitative measures. AHP is a decision-making method developed to give priority to several alternatives when several criteria must be considered and allows the decision maker to arrange complex problems into a hierarchical form or a series of integrated levels [1].

AHP is relatively easy to understand and use. Many studies on supplier selection problems use this method. AHP is an ideal method to provide an alternative ranking / sequence when several criteria and sub-criteria are in the decision making. Several criteria that are influential and commonly used in supplier selection include the criteria for price, quality, delivery accuracy and warranty [2].

\section{RESEARCH METHODS}

The beginning of the Analytic Hierarchy Process (AHP) research method was to arrange a hierarchy of the main objectives along with the accompanying criteria, sub-criteria and alternatives. The hierarchical structure of the problem of determining priority vendors in the selection of propylene glycol raw materials at this company is arranged into four levels as shown in Fig.1 below.

Based on the hierarchical structure in Fig. 1, it can be seen that the authors divide the hierarchical structure into four levels, namely: objectives, criteria, sub-criteria and alternatives. Purpose is the level that becomes the final result (output) to be achieved from the implementation of this research process. The criteria and sub-criteria in this study are the criteria and sub-criteria used by the company in selecting partners or partners (vendors) obtained from the results of a questionnaire at the initial stage of the study. The alternative level shows the five names of companies that are partners or work partners (vendors).

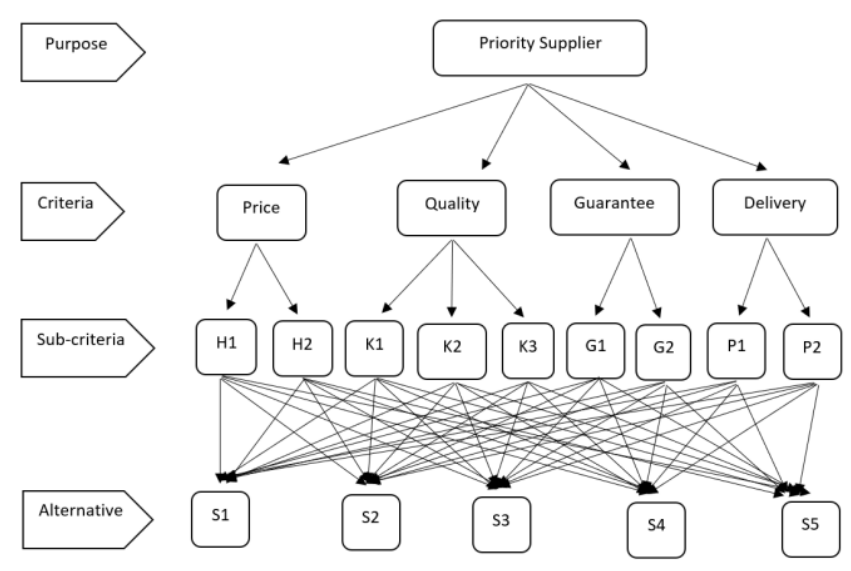

Detail:

H1: Price appropriateness with the quality of the goods produced $\mathrm{H} 2$ : The ability to provide discounts (discounts) on orders in a certain amount

$\mathrm{K} 1$ : The conformity of goods with predetermined specifications

$\mathrm{K} 2$ : Provision of flawless goods

$\mathrm{K} 3$ : Ability to provide consistent quality

G1: Time limit for complaint

$\mathrm{G} 2$ : Ease of submitting a claim process

P1: The ability to deliver goods according to the agreed date

P2: Ability in terms of handling the transportation system

S1 : Supplier A

S2 : Supplier B

S3 : Supplier C

S4 : Supplier D

S5 : Supplier E

Fig. 1. Hierarchy Structure for Determining Priority Supplier. Source: Source: Q1 2019 business review report.

Analytical Hierarchy Process overcome the problem with the approach of weight (weight) and scores (value). This is done by structuring complexity as a hierarchy and measuring ratio scales through pairwise relative comparisons. The use of redundancy allows accurate priority to be taken from verbal judgments. We can use words to compare qualitative factors and obtain priority scale ratios that can be combined with quantitative factors. Using the AHP pairwise comparison process, the weights or priorities are obtained from a set of judgments. When it is difficult to justify an arbitrary weight set, it is actually relatively easy based on the raw data, knowledge, and experience of the decision. This weight or priority is a measurement of the ratio level, not calculated. From the weighting obtained using the super decision application, the resulting graph Table III regarding the comparison between the criteria as follows.

\begin{tabular}{|c|c|c|}
\hline \multicolumn{3}{|c|}{ TABLE III: COMPARISON BETWEEN CRITERIA } \\
\hline Criteria & Eign Value & CR Value \\
\hline Guarantee & 0,04032 & 0,08445 \\
\hline Price & 0,58252 & 0,08445 \\
\hline Quality & 0,14162 & 0,08445 \\
\hline Delivery & 0,23553 & 0,08445 \\
\hline
\end{tabular}

From the data above, it can be seen that the Eign value for the price is 0.58252 where this value is the highest value of the Eign value from other criteria. This means that price is the criteria most used as a reference for companies in selecting suppliers of propylene glycol. Then followed by shipments in the second rank of 0.23553 and the quality criteria of 0.14162 . The warranty criteria occupy the last 
position in the ranking of criteria which is used as a decision in choosing a propylene glycol supplier. The $C R$ value, which is 0.08445 , is smaller than 0.1 , which means that the consistency of the criteria is acceptable or valid.

TABLE IV: COMPARISON BETWEEN CRITERIA

\begin{tabular}{ccc}
\hline Sub-criteria H1 & Eign Value & CR Value \\
\hline S1 & 0,13324 & 0,03265 \\
S2 & 0,07937 & 0,03265 \\
S3 & 0,33831 & 0,03265 \\
S4 & 0,19333 & 0,03265 \\
S5 & 0,25575 & 0,03265 \\
\hline
\end{tabular}

Source: Super Decision Software.

From the data above, it can be seen that the supplier chart number 3, namely Supplier C, has the highest Eign value on the price appropriateness sub-criteria with the quality of the goods produced with a value of 0.33831 followed by supplier number 5 , namely 0.25575 . There is a $C R$ value of 0.03265 which is smaller than $10 \%$, meaning that the results are consistent and can be accepted or valid.

\begin{tabular}{ccc}
\multicolumn{3}{c}{ TABLE V: COMPARISON BETWEEN CRITERIA } \\
\hline Sub-criteria H2 & Eign Value & CR Value \\
\hline S1 & 0,15268 & 0,07228 \\
S2 & 0,09452 & 0,07228 \\
S3 & 0,36455 & 0,07228 \\
S4 & 0,12391 & 0,07228 \\
S5 & 0,26433 & 0,07228 \\
\hline
\end{tabular}

Source: Super Decision Software.

In Table $\mathrm{V}$ above, it can be seen that the supplier chart number 3, namely Supplier C has the highest Eign value on the sub-criteria the ability to give discounts on orders in a certain amount with a value of 0.36455 then followed by supplier number 5 in ranking the second is 0.26433 . There is a CR value of 0.07228 which is smaller than $10 \%$, which means that the CR matrix carried out on the consistency test of the subcriteria is consistently acceptable or valid.

\begin{tabular}{ccc}
\multicolumn{3}{c}{ TABLE VI: COMPARISON BETWEEN CRITERIA } \\
\hline Sub-criteria K1 & Eign Value & CR Value \\
\hline S1 & 0,15048 & 0,05695 \\
S2 & 0,06158 & 0,05695 \\
S3 & 0,26039 & 0,05695 \\
S4 & 0,19795 & 0,05695 \\
S5 & 0,32958 & 0,05695 \\
Source: Super Decision Software.
\end{tabular}

In Table VI above, it can be seen that the supplier chart number 5, namely Supplier E has the highest Eigen value on the sub-criteria of conformity to goods with predetermined specifications with a value of 0.32958 followed by supplier number 3 in the second rank, which is 0.26039 . There is a CR value of 0.05695 which is smaller than $10 \%$, meaning that the CR matrix carried out on the consistency test of the sub-criteria is consistently acceptable or valid.

TABLE VII: COMPARISON BETWEEN CRITERIA

\begin{tabular}{ccc}
\hline \multicolumn{2}{c}{ TABLE VII: COMPARISON BETWEEN CRITERIA } \\
\hline S1 & Eign Value & CR Value \\
S2 & 0,18309 & 0,03265 \\
S3 & 0,09538 & 0,03265 \\
S4 & 0,24219 & 0,03265 \\
S5 & 0,13840 & 0,03265 \\
\hline
\end{tabular}

Source: Super Decision Software.
In Table VII above, it can be seen that the supplier chart number 5, namely Supplier E has the highest Eigen value on the sub-criteria for the provision of defective goods with a value of 0.34092 then followed by supplier number 3 in the second rank, which is 0.24220 . There is a CR value of 0.03265 which is smaller than $10 \%$, meaning that the CR matrix carried out on the consistency test of the sub-criteria is consistently acceptable or valid.

\begin{tabular}{|c|c|c|}
\hline $\begin{array}{r}\text { TABLE VIII } \\
\text { Sub-criteria K3 }\end{array}$ & $\begin{array}{l}\text { IPARISON BET } \\
\text { Eign Value }\end{array}$ & $\begin{array}{l}\text { CRITERIA } \\
\text { CR Value }\end{array}$ \\
\hline $\mathrm{S} 1$ & 0.09139 & 0,01993 \\
\hline S2 & 0.06312 & 0,01993 \\
\hline S3 & 0.28775 & 0,01993 \\
\hline S4 & 0.14444 & 0,01993 \\
\hline S5 & 0.41328 & 0,01993 \\
\hline
\end{tabular}

In Table VIII above, it can be seen that the supplier chart number 5, namely Supplier E has the highest Eigen value on the Ability sub-criteria to provide consistent quality with a value of 0.41328 then followed by supplier number 3 in the second rank, namely 0.28776 . There is a CR value of 0.01993 which is smaller than $10 \%$, meaning that the CR matrix carried out on the consistency test of the sub-criteria is consistently acceptable or valid.

\begin{tabular}{ccc}
\multicolumn{3}{c}{ TABLE IX: COMPARISON BETWEEN CRITERIA } \\
\hline Sub-criteria G1 & Eign Value & CR Value \\
\hline S1 & 0.18216 & 0,01710 \\
S2 & 0.10965 & 0,01710 \\
S3 & 0.24186 & 0,01710 \\
S4 & 0.06767 & 0,01710 \\
S5 & 0.39863 & 0,01710 \\
\hline
\end{tabular}

Source: Super Decision Software.

In Table IX above, it can be seen that the supplier chart number 5, namely Supplier E has the highest Eigen value on the complaint deadline sub-criteria with a value of 0.39864 then followed by supplier number 3 in the second rank, which is 0.24187 . There is a CR value of 0.01710 which is smaller than $10 \%$, meaning that the $\mathrm{CR}$ matrix carried out on the consistency test of the sub-criteria is consistently acceptable or valid.

TABLE X: COMPARISON BETWEEN CRITERIA

\begin{tabular}{ccc}
\multicolumn{3}{c}{ TABLE X: COMPARISON BETWEEN CRITERIA } \\
\hline Sub-criteria G2 & Eign Value & CR Value \\
\hline S1 & 0.07281 & 0,02045 \\
S2 & 0.11918 & 0,02045 \\
S3 & 0.24872 & 0,02045 \\
S4 & 0.18747 & 0,02045 \\
S5 & 0.37179 & 0,02045 \\
\hline
\end{tabular}

Source: Super Decision Software.

In TabX above, it can be seen that the supplier chart number 5, namely Supplier E has the highest Eigen value in the sub-criteria for the ease of submitting a claim process with a value of 0.37179 followed by supplier number 3 in the second rank, which is 0.24872 . The CR value of 0.02045 is less than $10 \%$, which means that the CR matrix carried out on the consistency test of the sub-criteria is consistent or valid. 
TABLE XI: COMPARISON BETWEEN CRITERIA

\begin{tabular}{ccc}
\hline Sub-criteria P1 & Eign Value & CR Value \\
\hline S1 & 0.22660 & 0,03231 \\
S2 & 0.05486 & 0,03231 \\
S3 & 0.16823 & 0,03231 \\
S4 & 0.10865 & 0,03231 \\
S5 & 0.44162 & 0,03231 \\
\hline
\end{tabular}

Source: Super Decision Software.

In Table XI above it can be seen that the supplier chart number 5, namely Supplier E has the highest Eigen value on the sub-criteria. The ability to deliver goods according to the agreed date with a value of 0.44163 then followed by supplier number 1 in the second rank, which is equal to 0 , 22661. The CR value of 0.03231 is less than $10 \%$, meaning that the CR matrix carried out on the consistency test of the sub-criteria is consistent or valid.

\begin{tabular}{ccc}
\multicolumn{3}{c}{ TABLE XII: COMPARISON BETWEEN CRITERIA } \\
\hline Sub-criteria P2 & Eign Value & CR Value \\
\hline S1 & 0.26300 & 0,02190 \\
S2 & 0.07109 & 0,02190 \\
S3 & 0.14552 & 0,02190 \\
S4 & 0.08952 & 0,02190 \\
S5 & 0.43085 & 0,02190 \\
\hline
\end{tabular}

Source: Super Decision Software.

In Table XII above, it can be seen that the supplier chart number 5, namely Supplier E has the highest Eigen value in the capability sub-criteria in terms of handling the transportation system with a value of 0.43085 followed by supplier number 1 in the second rank, which is 0.26301 . The CR value of 0.02190 is less than $10 \%$, meaning that the CR matrix carried out on the consistency test of the sub-criteria is consistently acceptable or valid.

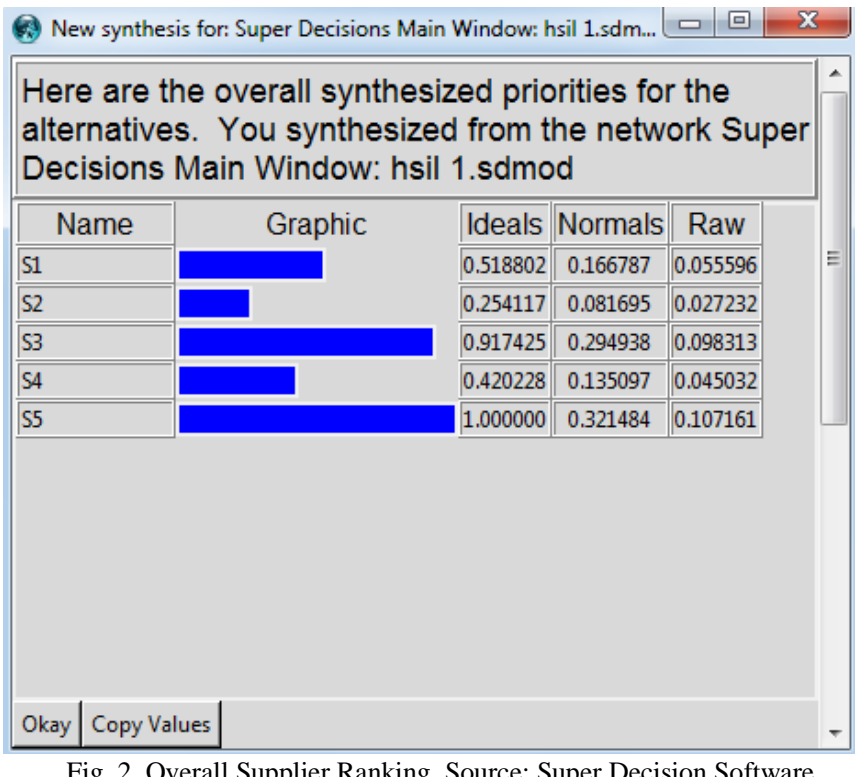

Fig. 2. Overall Supplier Ranking. Source: Super Decision Software.

In Fig. 2 above, it can be seen that the supplier chart number 5, Supplier E, is in the first place as the top priority supplier, then ranked second for supplier priority to supplier number 3, namely Supplier C and in third position for supplier priority, namely supplier number 1 , namely Supplier A. Then in the fourth position for supplier priority, namely Supplier D and the last one as supplier with the last priority, namely Supplier B according to the final weighting results using the super decision software.

\section{CONCLUSION AND Suggestion}

\section{A. Conclusions}

Based on the overall results of data processing and analysis of assessments carried out on the performance of propylne glycol suppliers using the Analytic Hierarchy Process (AHP) method, three main points or conclusions can be drawn from the results of the research, each of which is the answer to the problem formulation in this study, namely as follows:

1. The measurement results of four supplier selection criteria, namely: price, quality, guarantee and delivery in the selection of propylne glycol suppliers using the Analytic Hierarchy Process (AHP) method have shown that the price criteria (price) ) is the most important priority that is considered by the company with the achievement of priority weight of 0.58252 which is then followed by the criteria for delivery, quality and warranty with each priority weight reaching 0.23553 ; 0.14162 and 0.04032

2. The results of the consistency level test based on the results of respondents' answers to the assessment of all criteria and sub-criteria in the selection of propylne glycol suppliers using the Analytic Hierarchy Process (AHP) method are declared valid and consistent. This result can be seen from the achievement of the Consistency Ratio (CR) value for each calculation at the criteria, sub-criteria and alternatives levels that are still within the tolerance threshold, which is below $10 \%$ or 0.1. The achievement of the Consistency Ratio (CR) value which reaches a number below $10 \%$ or 0.1 is a reference that all answers given by respondents in the questionnaire distributed can be accepted and declared consistent and feasible to continue into the process of calculating the Analytic method Hierarchy Process (AHP).

3. The results obtained by the priority supplier based on the overall Analytic Hierarchy Process (AHP) method (global priority) are that Supplier E suppliers are included in the first global priority order and the second priority is achieved by the next alternative, namely PT SMPD suppliers.

\section{B. Suggestions}

Based on the results of research related to the analysis of propyne glycol supplier selection using the Analytic Hierarchy Process (AHP) method, the authors provide suggestions related to the following research:

1. Companies are advised to prioritize price criteria in selecting suppliers (work partners) and follow it with delivery criteria, quality criteria and guarantee criteria. This is clearly very reasonable because as a company that is engaged in the field of food raw materials where currently there are many new competitors who continue to erode the market from the bottom with cheaper prices and faster product availability will greatly affect the company's image (image) of the company in competitiveness at the level of competitors which will have an impact on sustainability business continuity in the future.

2. The use of suppliers that keep changing as a result of the large number of suppliers entering into the 
procurement of one activity of the same raw material, has clearly shown that there is no good optimization from the company side which results in low levels of efficiency in terms of costs and low levels of effectiveness in terms of operational processes company.

3. The best main supplier in global priority is Supplier E. The results of calculations that have been carried out using the Analytic Hierarchy Process (AHP) method can be used as a reference for the criteria and subcriteria expected by the company from a vendor (partner).

4. If in the actual field process that occurs, the main supplier experiences limitations or shortcomings in the process of fulfilling the request, then he can appoint a second alternative supplier to be used as an alternative option for meeting field operational needs but still with the portion of the main supplier as a more dominant priority because it is appropriate with the criteria set by the company in order to achieve a more optimal process (efficient and effective).

\section{REFERENCES}

[1] Azis, Iwan J. Dkk. (2010). Sustainable Development: Role and ContributionEmil Salim, Jakarta: KPG (Popular Gramedia Library).

[2] Pujawan, I.N. \& Mahendrawathi. (2017). Supply Chain Management, 3rd edition Yogyakarta: Andi.

[3]

[4] Avila, P; Mota A, Pires A, Bastos J, Putnik G, and Teixeira J. (2012). Supplier's Selection Model Based on an Empirical Study. Procedia Technology, Vol.5, pp.627.

[5] Dickson, G W. (1966). An analysis of vendor selection systems and decisions. Journal of Purchasing, Vol.2 (1), pp.5-17.

[6] Saaty, T. L. \& Kearns, K. P. (1985). Analytical Planning the Organization of Systems. Pergamon Press.

[7] Saaty, T. L. (1994). Fundamentals of Decision Making and Priority Theory, RWS Publications, Pittsburgh.

[8] Saaty, T.L. (2005). Theory and Applications of the Analytic Network Process: Decision Making with Benefits, Opportunities, Costs, and Risks. RWS Publications, USA. 